\title{
Impact of solar radiation on chemical structure and micromechanical properties of cellulose-based humidity-sensing material Cottonid
}

\author{
R. Scholz ${ }^{*}$ (D, M. Langhansl' ${ }^{2}$, M. Hemmerich ${ }^{3}$, J. Meyer $^{3}$, C. Zollfrank ${ }^{2}$ and F. Walther ${ }^{1}$
}

\begin{abstract}
Renewable and environmentally responsive materials are an energy- and resource-efficient approach in terms of civil engineering applications, e.g. as so-called smart building skins. To evaluate the influence of different environmental stimuli, like humidity or solar radiation, on the long-term actuation behavior and mechanical robustness of these materials, it is necessary to precisely characterize the magnitude and range of stimuli that trigger reactions and the resulting kinetics of a material, respectively, with suitable testing equipment and techniques. The overall aim is to correlate actuation potential and mechanical properties with process- or application-oriented parameters in terms of demand-oriented stimuli-responsive element production. In this study, the impact of solar radiation as environmental trigger on the cellulose-based humidity-sensing material Cottonid, which is a promising candidate for adaptive and autonomously moving elements, was investigated. For simulating solar radiation in the lab, specimens were exposed to short-wavelength blue light as well as a standardized artificial solar irradiation (CIE Solar ID65) in long-term aging experiments. Photodegradation behavior was analyzed by Fourier-transform infrared as well as electron paramagnetic resonance spectroscopy measurements to assess changes in Cottonid's chemical composition. Subsequently, changes in micromechanical properties on the respective specimens' surface were investigated with roughness measurements and ultra-micro-hardness tests to characterize variations in stiffness distribution in comparison to the initial condition. Also, thermal effects during long-term aging were considered and contrasted to pure radiative effects. In addition, to investigate the influence of process-related parameters on Cottonid's humidity-driven deformation behavior, actuation tests were performed in an alternating climate chamber using a customized specimen holder, instrumented with digital image correlation (DIC). DIC was used for precise actuation strain measurements to comparatively evaluate different influences on the material's sorption behavior. The infrared absorbance spectra of different aging states of irradiated Cottonid indicate oxidative stress on the surface compared to unaged samples. These findings differ under pure thermal loads. EPR spectra could corroborate these findings as radicals were detected, which were attributed to oxidation processes. Instrumented actuation experiments revealed the influence of processing-related parameters on the sorption behavior of the tested and structurally optimized Cottonid variant. Experimental data supports the definition of an optimal process window for stimuli-responsive element production. Based on these results, tailor-made functional materials shall be generated in the future where stimuli-responsiveness can be adjusted through the manufacturing process.
\end{abstract}

\footnotetext{
* Correspondence: ronja.scholz@tu-dortmund.de

'Department of Materials Test Engineering (WPT), TU Dortmund University,

Baroper Str. 303, D-44227 Dortmund, Germany

Full list of author information is available at the end of the article
}

Springer Open (c) The Author(s). 2021 Open Access This article is licensed under a Creative Commons Attribution 4.0 International License, which permits use, sharing, adaptation, distribution and reproduction in any medium or format, as long as you give appropriate credit to the original author(s) and the source, provide a link to the Creative Commons licence, and indicate if changes were made. The images or other third party material in this article are included in the article's Creative Commons licence, unless indicated otherwise in a credit line to the material. If material is not included in the article's Creative Commons licence and your intended use is not permitted by statutory regulation or exceeds the permitted use, you will need to obtain permission directly from the copyright holder. To view a copy of this licence, visit http://creativecommons.org/licenses/by/4.0/. 


\section{Introduction and state of the art}

Stimuli-responsive materials inspired by the natural behavior of biological structures, like plants, are adaptive elements in various applications, viz. in biomedicine for drug delivery, in microfluidics and robotics as well as in bioarchitecture for development of e.g. climate-adaptive shading systems [1]. With regard to each application, different stimuli are relevant and, range e.g. from temperature and relative humidity to light and radiation. In bioarchitecture, the passive humidity-driven shape change of cellulose-based materials, like plants and wood, in reaction to changing environmental, i.e. weathering, conditions is used for an energy-efficient conversion of primary energy into a kinetic one. Consequently, it is in the nature of things, that these adaptive construction materials are additionally exposed to elevated temperatures and ultraviolet (UV) light during service, and it is of high relevance to characterize their thermal and radiation induced degradation behavior and its effect on their long-term material properties [2]. Since adaptivity to external stimuli, like temperature or relative humidity, is the condition for an efficient technical usage of weathering conditions within bioarchitecture, mostly polymer-based material systems, especially wood, are used for the development of so-called smart building skins [3].

In this context, Cottonid is a cellulose-based humiditysensing material manufactured by the parchmentizing process, which exhibits great potential for the production of climate-adaptive elements with tailor-made material properties [4]. This study focusses the impact of solar radiation on chemical structure and micromechanical properties of Cottonid. It is an extract of a comprehensive experimental study on the influence of individual manufacturing parameters on the functional and mechanical properties of the biopolymeric material by means of instrumented actuation and fatigue assessments. The results are used for application-oriented structural optimization of Cottonid for applications for adaptive construction materials by adjustment of the manufacturing process.

The results presented were obtained by a combination of non-destructive analytical and micromechanical investigations to build up a more profound knowledge about Cottonid's interaction with its environment and the effect of long-term exposure to weathering conditions on its structure-property-relationships on the exposed surface. In the next step, the effect on the macromechanical properties will be investigated by the help of instrumented quasi-static and fatigue experiments.

Bioinspired, stimuli-responsive materials for constructionrelated applications

In response to external stimuli, like temperature, relative humidity or light etc., stimuli-responsive polymer-based material systems are able of autonomous reactions, e.g. adaptive shape changing, which is an energy-efficient way of producing kinetic energy or a mechanical force due to volume expansion. Therefore, nowadays in terms of energy-efficiency and eco-friendliness this bio-inspired mechanism is very interesting for implementation in technical and engineering issues. Applications fields are various and range from microfluidics over soft robotics to socalled bioarchitectural topics, where smart building skins respond to changing weathering conditions with adaptive reactions. E.g., with increasing temperature, single façade elements expand to provide shading and shrink, when temperatures are decreasing again, so that they are not permanently blocking the sight out of the building. In case of cellulose-based materials, like wood, the decisive stimulus, which activates the adaptive reactions, is humidity. Due to hygroscopic water uptake from the surrounding environment, cellulose micro fibrils swell perpendicular to their orientation within the material and cause a passive shape change, whose magnitude and direction is programmed in the microstructure [5]. This behavior can be observed for various plant systems, where the microstructure of the cell walls is used for directed swelling and shrinking processes $[3,6]$. These biological moving concepts have been an inspiration for the development of a variety of bio-inspired actuators for different applications in recent years to introduce the efficient relationship between structure and function by development of new functional materials [7-9]. The available actuation concepts, like one-dimensional bending, which is realized over bilayered systems, with one active and one passive layer with regard to the present stimulus, two-dimensional stretching, buckling or three-dimensional volume expansion, can be adjusted by the microstructure of the polymer-based material systems and have their specific advantages and disadvantages with respect to the intended application. Also, a combination of these deformation modes in one actuator system is conceivable by microstructural tuning. Furthermore, the development of systems that respond to multiple external stimuli in a smart and foreseeable way is in the focus of current research [1, 3, 10]. Additionally, experiments with chemical degradation of matrix polymers to retain just the more porous cellulose scaffold for functionalization have been conducted. Besides usage of the dimensional instability when in contact with humidity in climateadaptive building shells, the material behavior can also be used for production of curved timber elements by specific upstream humidity treatment and intelligent combination of layers with different micro fibril angles [5, 11].

Therefore, smart building skins play an important role in the required global reduction of energy consumption, since autonomous, humidity-driven wood bilayers can serve as an energy-efficient alternative to motor-driven 
façade shading elements [12]. To assess the performance of the systems, especially the long-term stability as well as the repeatability of the humidity-driven movements, instrumented test setups, which simulate outdoor weathering conditions have been developed using environmental chambers and materials' reactions have been characterized, e.g. by optical monitoring of the swelling and shrinkage strains, measurements of changes in temperature, moisture content or other material specific parameters. Furthermore, the effect of different humidity cycles, slow and fast cycles in high and low humidity ranges, where investigated. During these experiments, a hysteresis was observed, when strains are plotted as function of relative humidity [13].

\section{Thermal and light-induced degradation mechanisms in cellulose-based materials}

As stated above, the properties of cellulose-based material systems are affected by environmental effects, like elevated temperatures, changing degrees of relative humidity as well as influence of oxygen and solar radiation, manifesting in e.g. discoloration, pronounced decrease of mechanical properties and embrittlement [14-16]. For cellulose, which is the most abundant biopolymer on earth and therefore intensively used as raw material for various stimuliresponsive material systems, the mechanism of photodegradation is induced by a superimposition of several radical reactions. An initial reaction is a decrease in degree of polymerization (DP) caused by scission of cellulose chains [17]. Yatagai and Zeronian investigated degradation mechanisms caused by ultraviolet (UV) irradiation, heat exposure and by a combination of both treatments. They revealed changes in color as well as formation of carbonyl, carboxyl and hydroperoxide groups, resulting in an additional decrease in $\alpha$-cellulose content. It was stated, that heat exposure alone caused reactions comparable to UV exposure [18]. Hon further observed a reaction of cellulosic carbon-centred radicals with oxygen molecules in electron paramagnetic resonance (EPR) studies, identifying oxygen as decisive reagent in photooxidative degradation of cellulose $[19,20]$.

In case of cellulose-based material systems, wood is one of the most important engineering and structural materials. Infrared spectroscopy studies on wood exposed to UV irradiation observed an increased amount of carboxylic and carbonyl chromophoric functional groups and a decreased amount in aromatic functional groups, respectively. In these studies, mainly ligninderived degraded products could be observed limited to the specimens' surfaces. Nevertheless, as stated above, degradation by sunlight or UV radiation, resulting in pronounced structural modifications, is also expected for the other chemical components (cellulose, hemicelluloses) [21]. Efficient methods for characterizing these changes in chemical structure are Fourier transform infrared (FTIR) and electron paramagnetic resonance (EPR) spectroscopy. EPR gives information about evolution of radicals related to radiation-induced degradation mechanisms and can be used to verify oxidation reactions that cause deviations from the initial IR spectra [22, 23].

To characterize the impact of degradation mechanisms on the long-term behavior of cellulose-based material systems in architectural applications, a precise simulation of outdoor weathering conditions has to be performed in the lab. Solar radiation envelopes a range from 200 to $2500 \mathrm{~nm}$, where highest irradiance levels are present in the visible part. For polymers, the UV part of the spectrum, which reaches the earth's surface, is the most critical one [24]. Therefore, the influence of shortwavelength visible radiation as well as thermal loads on the long-term material properties in the already described application field is of high importance. Further, it is an advantage for research, if aging experiments could be accelerated while simultaneously not changing the temperature due to radiative energy input and hence keeping the causes for degradation viz. temperature and radiation separated. On this topic, Baltscheit et al. [25] and Hemmerich et al. [26, 27] report on the simulation of the aging behavior of transparent bioplastics, like polyactide, under accelerated artificial conditions with prioritizing effects under blue light radiation with shortwavelength and high energy.

\section{Cottonid material system}

Cellulose as most abundant biopolymer on earth and therefore a very sustainable resource is an attractive material candidate for substitution of fossil products in specific, i.e. mostly functional, applications as stated above. Besides native cellulose, cellulose derivates, like e.g. regenerated or oxidized cellulose containing cellulose II crystals, are favored because of their simple and reproducible way of manufacturing. For this material class, the amount of inter- and intramolecular hydrogen bonds is very important for the physical properties of cellulosic commercial products [28]. For the above rendered adaptive applications, pure cellulosic materials often show a more pronounced swelling and shrinking behavior in comparison to composite materials like wood. In this case, Cottonid is a modified natural material fully based on partly modified cellulose and appears to be a mix of cellulose I and II. Based on unsized raw paper, chemical modification is achieved by a treatment with a warm zinc dichloride $\left(\mathrm{ZnCl}_{2}\right)$ or sulphuric acid $\left(\mathrm{H}_{2} \mathrm{SO}_{4}\right)$ solution, called parchmentizing [29, 30]. The temperature of the catalyst bath $\mathrm{T}_{\text {cat }}$ and the reaction time $t_{\text {react }}$ in it define the amount of inter- and intramolecular hydrogen bonds that are newly formed [4, 31, 32]. These are, as stated above, important for the final 
mechanical and physical properties. Since nowadays this well known material gains new relevance in technical and especially climate-adaptive applications, Scholz et al. performed an experimental assessment to qualify Cottonid in general for technical applications compared to established materials, like synthetic plastics and wood [33], as well as to assess the influence of individual manufacturing parameters on the amount of hydrogen bonds present and therefore on the functional and mechanical properties of Cottonid [34-36]. Furthermore, the impact of outdoor weathering conditions on the long-term actuation and fatigue behavior is characterized. The aim is to structurally optimize Cottonid [37] through adjustment of the manufacturing process for the production of Cottonid elements with tailor-made properties for either adaptive or constructive applications.

\section{Materials and methods}

\section{Sample preparation}

For aging experiments, specimens were cut out of a plate of industrial Cottonid material (Ernst Krueger, Geldern, Germany) with a thickness of $t_{\text {mat }}=2.0 \mathrm{~mm}$.

For actuation experiments, specimens were cut out of plates of the structurally optimized Cottonid variant M60Z50 with material thicknesses of $t_{\text {mat,thin }}=0.4 \mathrm{~mm}$ and $\mathrm{t}_{\text {mat,thick }}=4.0 \mathrm{~mm}$. Unsized raw paper (weight $=320 \mathrm{~g} / \mathrm{m}^{2}$, $\mathrm{t}_{\mathrm{mat}}=0.9 \mathrm{~mm}$, Hahnemuehle, Dassel, Germany), which fully consists of cotton linters, subsequently marked as "M", was used for the production of M60Z50. For chemical treatment, a 70 wt-\% zinc dichloride $\left(\mathrm{ZnCl}_{2}\right)$ solution, subsequently marked as " $Z$ ", is used as catalyst. The sample name of the resulting Cottonid variants is a combination of the chosen manufacturing parameters (Table 1). The samples are then smoothed and dried in a calender (Sumet, Denklingen, Germany) under pressure and temperature. In order to prevent a dimensional change of the material due to water absorption from the environment, the samples are stored under weight in a dry atmosphere until further analysis [35]. Caused by the manufacturing process, the cellulose micro fibrils in the paper layers have a preferred orientation in manufacturing direction [33]. So depending on specimen location within the Cottonid sheet, varying actuation and mechanical properties, respectively, are expected, Fig. 1a. Actuator type I was chosen to characterize humidity-driven swelling and shrinking behavior perpendicular to micro fibril axis, Fig. $1 \mathrm{~b}$.

For conditioning, specimens were stored under laboratory conditions (temperature $\mathrm{T}=23 \pm 2{ }^{\circ} \mathrm{C}$, relative humidity $\phi=35 \pm 5 \%$ ) for a time $t_{\text {cond }}>48 \mathrm{~h}$ before testing.

\section{Aging experiments}

The aging experiments were performed under certain combinations of temperature T and relative humidity $\phi$, which especially in case of $\phi$ were dependent on the used device but not controllable. So, the changes in material properties discussed in this study are only relevant for these special environmental parameters. Differences can be expected if higher humidities and/or higher temperatures had been used in both the heat and UV exposures [17].

\section{Short-wavelength blue light and temperature}

Aging experiments under short-wavelength blue light were performed in a customized test setup for accelerated optical aging of materials under predefined, constant conditions, developed by the authors [25-27]. The main component of the test setup is a double-wall specimen chamber out of high-quality steel, which is thermostatted by a continuous circulation of water and equipped with thermocouples for the measurement of temperature in the chamber and on the specimens' surfaces. The cooling ensures, that temperature of transparent specimens can be controlled between $<10^{\circ} \mathrm{C}$ and $>90^{\circ} \mathrm{C}$ independent of the induced radiant power. For aging, a blue multi-chip-on-board high-performance LED (CLU048-1818C4-B455-XX, Citizen Electronics, Kamikurechi, Japan) is mounted above the specimen. The irradiance on the specimens' surfaces by the LED were calculated using a raytracing simulation. By monitoring and saving of the operating parameters, a controlled and traceable optical aging of specimens is realized [27].

Industrially manufactured Cottonid specimens for aging experiments have a unique red color intended as marketing and recognition factor for the product. The temperature on surface due to absorption (of the blue LED light) was $\mathrm{T}_{\text {aging }} \sim 75^{\circ} \mathrm{C}$. Averaged irradiance was $12.8 \mathrm{~kW} / \mathrm{m}^{2}$ for an aging time of $\mathrm{t}_{\mathrm{aging}}=3352 \mathrm{~h}$. Relative humidity was measured directly after the LED was turned off and was $\phi_{\text {LED }} \sim 56 \%$.

To separate degradation mechanism due to thermal and radiative loading, respectively, further specimens were thermally aged in an oven (UF 110 PLUS, Memmert, Schwabach, Germany) at $\mathrm{T}_{\text {aging }}=75^{\circ} \mathrm{C}$ also for $t_{\text {aging }}=3352 \mathrm{~h}$. Relative humidity was $\phi_{\text {oven }} \sim 0 \%$.

\section{Solar radiation}

For simulation of solar radiation in the lab, in order to verify the comparability of LED irradiation in the blue

Table 1 Sample designation of structurally optimized Cottonid

\begin{tabular}{lllll}
\hline Cottonid variant & Cellulose source & Reaction time & Catalyst & Temperature \\
\hline M60Z50 & Cotton linters $\left.{ }_{(\prime} \mathrm{M}^{\prime \prime}\right)$ & $60 \mathrm{~s}$ & Zinc dichloride solution $\left({ }_{\prime \prime} Z^{\prime \prime}\right)$ & $50^{\circ} \mathrm{C}$ \\
\hline
\end{tabular}



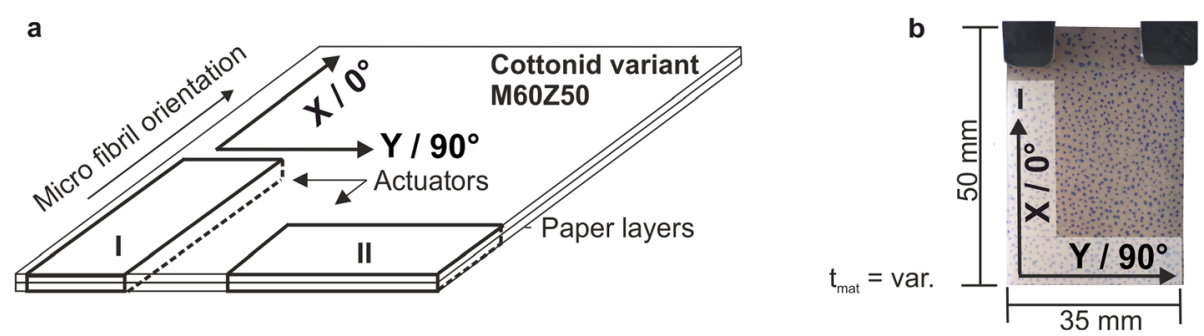

Fig. 1 Specimen preparation for actuation experiments: a Specimen location in Cottonid sheet according to manufacturing direction of paper layers, and $\mathbf{b}$ Cottonid actuator type I with speckled surface for strain measurements via digital image correlation (DIC) mounted in customized specimen holder

spectral region, further specimens were exposed to standardized artificial solar radiation (CIE Solar ID65) in a commercial xenon weathering chamber (Suntest XLS+, Atlas, Altenhasslau) with averaged irradiance of $2 \mathrm{~kW} /$ $\mathrm{m}^{2}$ for an aging time of $\mathrm{t}_{\text {aging }}=3352 \mathrm{~h}$. Temperature was $\mathrm{T}_{\text {aging }}=75^{\circ} \mathrm{C}$ with a relative humidity of $\phi_{\text {sun }} \sim 11.2 \%$.

\section{Structural investigations}

Infrared and electron paramagnetic resonance spectroscopy

For analysis of changes in chemical structure due to thermal and light-induced degradation mechanisms, FTIR spectroscopy was utilized (Nicolet iS50, Thermo Fisher Scientific, Waltham, Massachusetts, USA). IR spectra after different durations of aging were obtained in the mid-IR range of 4000 to $400 \mathrm{~cm}^{-1}$ in attenuated total reflection mode (ATR). Since the reflection mode investigates the surface, a correlation with the ultramicro-hardness measurements was possible. Twenty scans were averaged at a resolution of $4 \mathrm{~cm}^{-1}$. A background scan was acquired for each sample and subtracted in the subsequent measurement. The software offers the possibility to correct the baseline drift and to automatically detect characteristic peaks.

For detection of organic radicals, which may form on the specimens' surfaces due to thermal and light-induced aging, electron paramagnetic resonance spectroscopy (EPR) (MiniScope MS 5000, Bruker, Billerica, Massachusetts, USA) was carried out on specimens aged with the standardized artificial solar irradiation (CIE Solar ID65). EPR spectra were obtained in a magnetic field range of 330 to $340 \mathrm{mT}$ at a microwave frequency of $\mathrm{f}=9.438 \mathrm{GHz}$ and five measurements were averaged.

\section{Surface roughness and ultra-micro-hardness testing}

Surface roughness of the specimens was assessed with the profile method according to DIN EN ISO 4288 using a mobile surface roughness tester (MarSurf M 300 C, Mahr, Goettingen, Germany). For each aging state, roughness values were calculated and averaged based on three sampling lengths $l_{\mathrm{r}}=2.5 \mathrm{~mm}$.
Instrumented ultra-micro-hardness measurements were performed using a dynamic ultra-micro-hardness tester (DUH 211, Shimadzu, Kyoto, Japan) and loadindentation depth curves were obtained according to DIN EN ISO 14577. The process consists of a loading and unloading phases, where the load is applied with a constant load rate up to a predetermined indentation force of $F_{\max }=98.09 \mathrm{mN}$. For each series of tests, five indentations per sample were made for each aging state. The change in Martens hardness $\triangle \mathrm{HM}$ as well as indentation modulus $E_{i t}$ due to thermal and light-induced degradation processes was calculated and related to the values in initial condition.

\section{Investigations on humidity-driven actuation behavior}

For characterization of the humidity-driven swelling and shrinking behavior of the structurally optimized Cottonid variant M60Z50, static actuation test were performed in an alternating climate chamber (MKF 115, Binder, Tuttlingen, Germany) at a temperature $\mathrm{T}_{\text {climate }}=23^{\circ} \mathrm{C}$ and a relative humidity $\phi_{\text {climate }}=95 \%$ for a swelling time of $t_{s}=2.75 \mathrm{~h}$, Fig. 2a. To allow for the hygroscopic expansion of the Cottonid specimen, a customized specimen holder was used, where one clamp is fixed and the other one is moveable, Fig. 2b. Actuation strains were measured using digital image correlation (DIC) (Limess, Krefeld, Germany), for this the specimens' surfaces were speckled with a traceable pattern, Fig. 2c. For optical monitoring of the movements, an encapsulated camera was used (Hero 5, GoPro, San Mateo, USA).

\section{Results and discussion \\ Infrared and electron paramagnetic resonance spectroscopy}

Infrared spectra of the initial condition of Cottonid were depicted in relation to the aged states thermal $\left(\mathrm{T}_{\text {aging }}=\right.$ $75^{\circ} \mathrm{C}$ for $\left.t_{\text {aging }}=3352 \mathrm{~h}\right)$ in Fig. 3 , optical $\left(12.8 \mathrm{~kW} / \mathrm{m}^{2}\right.$ at $\mathrm{T}_{\text {aging }}=75^{\circ} \mathrm{C}$ for $\left.\mathrm{t}_{\text {aging }}=3352 \mathrm{~h}\right)$ in Fig. 4 and sun $(2$ $\mathrm{kW} / \mathrm{m}^{2}$ at $\mathrm{T}_{\text {aging }}=75^{\circ} \mathrm{C}$ for $t_{\text {aging }}=3352 \mathrm{~h}$ ) in Fig. 5 . The spectra were collected in a wavelength interval between 4000 and $400 \mathrm{~cm}^{-1}$ and all of them show the 

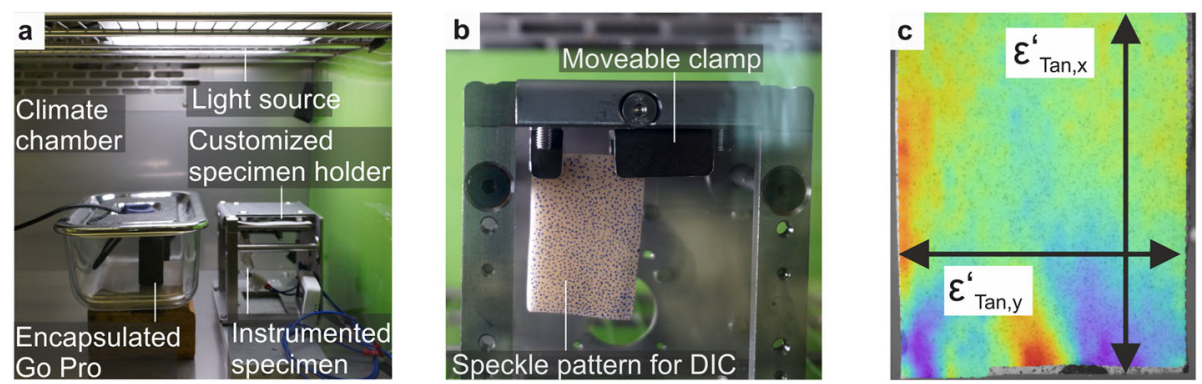

Fig. 2 a Test setup for actuation experiments in alternating climate chamber (MKF 115, Binder, Tuttlingen, Germany); b Cottonid specimen with speckled surface for strain measurements via digital image correlation (DIC) mounted in customized specimen holder; c Strain measurements on specimen's surface via DIC parallel $\left(\varepsilon_{\text {Tan,x }}^{\prime}\right)$ and perpendicular $\left(\varepsilon_{\text {Tan,y }}^{\prime}\right)$ to manufacturing direction

characteristic peaks for cellulose, which are defined in the initial condition spectra. In the interval between 3600 and $3100 \mathrm{~cm}^{-1}$ the stretching vibrations of the hydroxyl groups $(v(-\mathrm{OH}))$ of the cellulose chains can be seen. The height and area of the peak provides information about inter- and intramolecular hydrogen bonds present in the material. The much lower peak at 2900 $\mathrm{cm}^{-1}$ is attributed to the stretching vibrations of the alkyle groups $(v(-\mathrm{CH}))$. Absorbed water is the reason for the peak at $1640 \mathrm{~cm}^{-1}$. In the interval between 1300 and $900 \mathrm{~cm}^{-1}$ peaks of the alcohols located on the cellulose chains can be observed. The peak of the glycosidic linkage, which is also known as amorphous peak, can be found at $898 \mathrm{~cm}^{-1}$ [38].

When comparing the spectrum in initial condition with the spectra of the different aging states it becomes clear, that a considerable change in absorption can be detected at $2900 \mathrm{~cm}^{-1}$ and between 1750 and 1740 $\mathrm{cm}^{-1}$, respectively, which indicates the presence of oxidative stress on the surface for all aging states. The close-ups of the interesting regions make the changes more visible. The increase of peaks in the range of 1750 and $1740 \mathrm{~cm}^{-1}$ results from the formation of carbonyl and carboxyl groups due to reactions with the surrounding oxygen. These reactions imply the splitting of cellulose chains on the surface and a decrease of degree of polymerization (DP) $[17-19,39]$. Therefore, the peak at $2900 \mathrm{~cm}^{-1}$ simultaneously decreases because of these oxidative reactions, indicating a degradation of $\mathrm{C}-\mathrm{H}$ combinations. These findings could also be verified by EPR spectroscopy, since formation of organic radicals could be detected with increasing aging time, see Fig. 6 [22]. The described reactions are most pronounced for specimens aged with the standardized artificial solar irradiation [17].

Another feature worth mentioning is the increase of the peak at $1644 \mathrm{~cm}^{-1}$, which stands for adsorbed water.
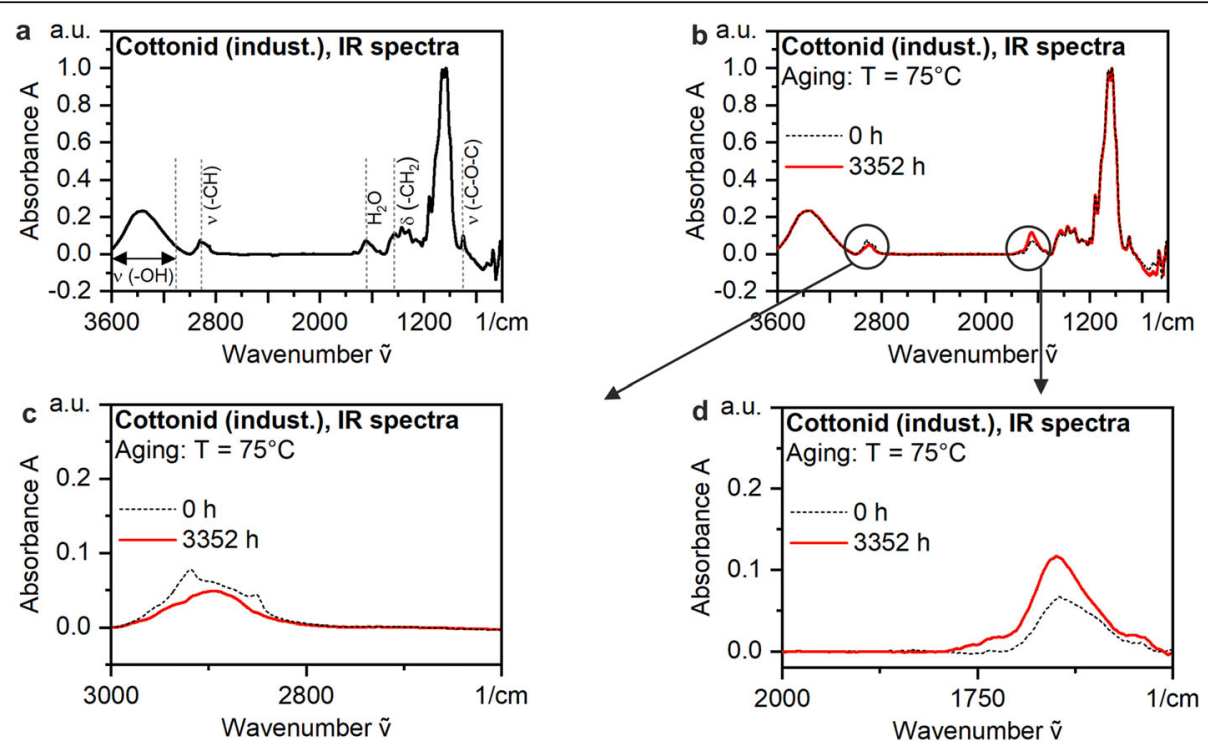

Fig. 3 Infrared (IR) spectra of industrial Cottonid material (Ernst Krueger): a In initial condition with peak definition of raw material cellulose, and $\mathbf{b}$ Comparative evaluation of initial condition and after thermal aging at $\sim 75^{\circ} \mathrm{C}$ for taging $=3352 \mathrm{~h}$; Peak evolution due to thermal aging: $\mathbf{c}$ Close-up at $\tilde{v}=2.900 \mathrm{~cm}^{-1}$, and $\mathbf{d}$ Close-up at $\tilde{\mathrm{v}} \sim 1.750 \mathrm{~cm}^{-1}$ 

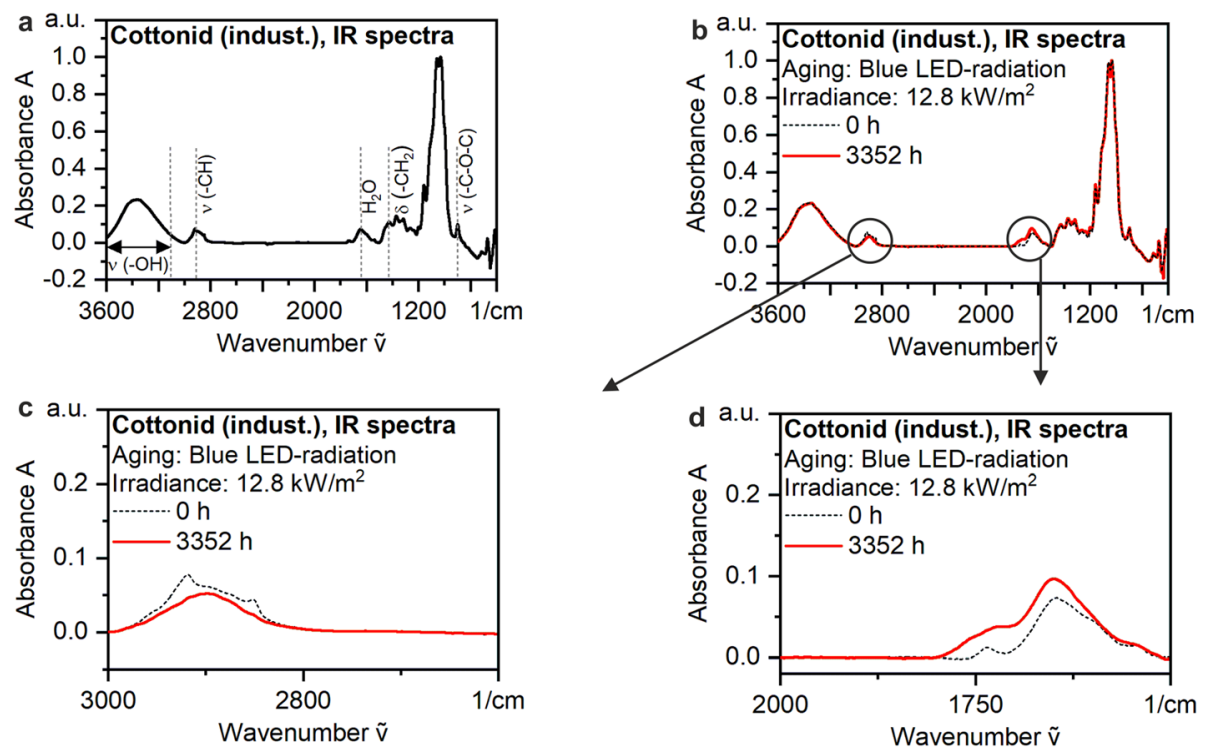

Fig. 4 Infrared (IR) spectra of industrial Cottonid material (Ernst Krueger): a In initial condition with peak definition of raw material cellulose, and $\mathbf{b}$ Comparative evaluation of initial condition and after optical aging (blue LED-radiation, irradiance: $12,8 \mathrm{~kW} / \mathrm{h}$ ) for taging $=3352 \mathrm{~h}$; Peak evolution due to optical aging: c Close-up at $\tilde{v}=2.900 \mathrm{~cm}^{-1}$, and $\mathbf{d}$ Close-up at $\tilde{v} \sim 1.750 \mathrm{~cm}^{-1}$

At first, it is not reasonable, that a specimen aged with temperature and light contains more water, since rather drying effects would be expected. Since the Cottonid specimens were taken out of the experimental setups for aging to collect IR and EPR spectra, the authors assume, that the material directly reacted with its surrounding again in taking up humidity from the ambient air.

\section{Roughness and ultra-micro-hardness testing}

Figure 7 shows the results of roughness measurements for the initial condition in comparison to the different aging states.

For evaluation of the change of surface roughness due to thermal and light-induced aging, averaged roughness depth $R_{z}$ and roughness value $R_{a}$ were obtained. In
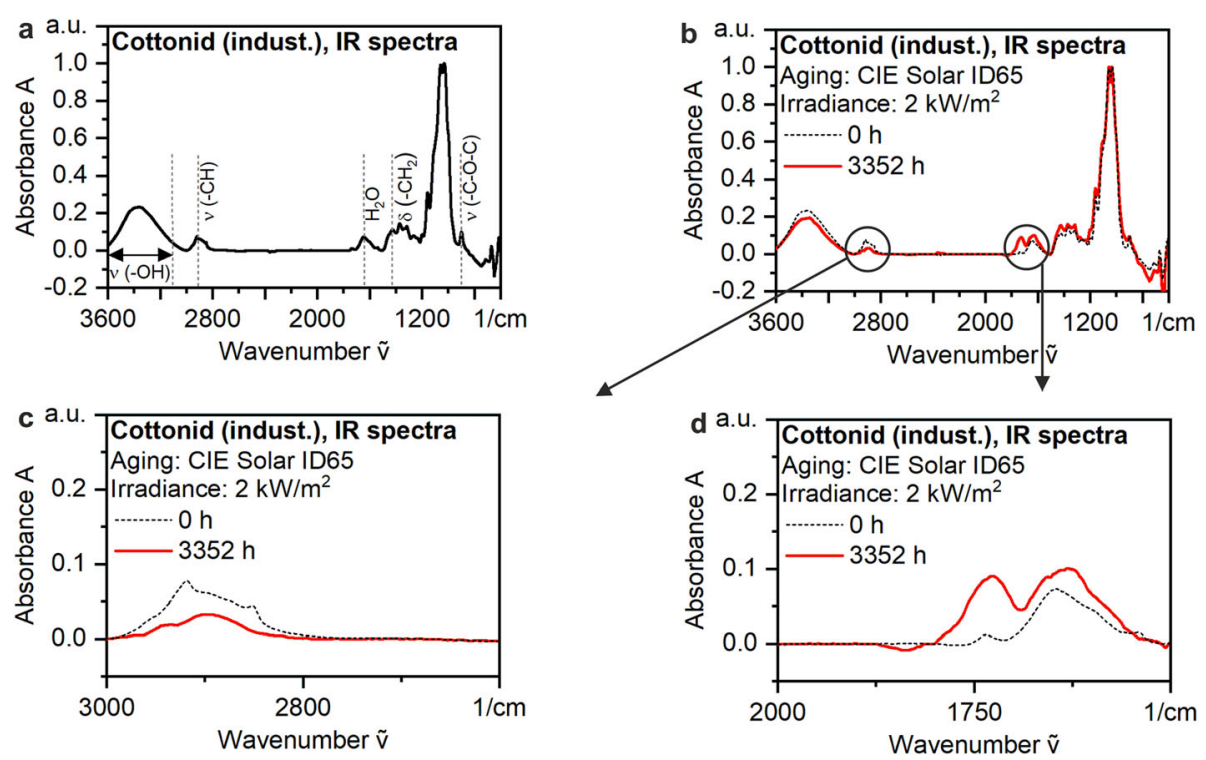

Fig. 5 Infrared (IR) spectra of industrial Cottonid material (Ernst Krueger): a In initial condition with peak definition of raw material cellulose, and $\mathbf{b}$ Comparative evaluation of initial condition and after optical aging (CIE solar ID65, irradiance: $2 \mathrm{~kW} / \mathrm{h}$ ) for $\mathrm{t}_{\text {aging }}=3352 \mathrm{~h}$; Peak evolution due to optical aging: $\mathbf{c}$ Close-up at $\tilde{v}=2.900 \mathrm{~cm}^{-1}$, and $\mathbf{d}$ Close-up at $\tilde{v} \sim 1.750 \mathrm{~cm}^{-1}$ 


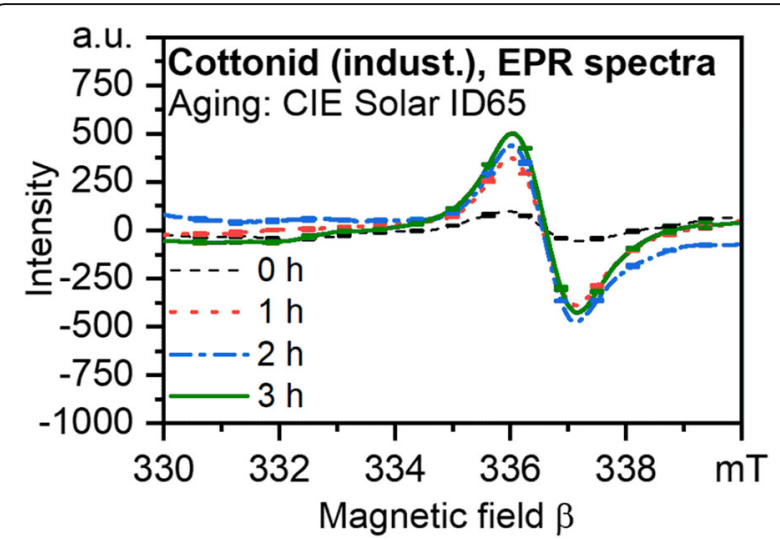

Fig. 6 Electron paramagnetic resonance (EPR) spectra of industrial Cottonid material (Ernst Krueger) in initial condition and after aging with standardized artificial solar irradiation (CIE solar ID65, irradiance: $2 \mathrm{~kW} / \mathrm{h}$ ) for increasing aging times

general, the aged specimens seem to have a lower roughness and especially when looking at $R_{z}$, a pronounced difference is visible between initial and sun. This finding correlates with studies of Hauptmann et al., where a decrease of nanoroughness of wood due to UV-irradiation accompanied by a change in color was observed [40, 41].

Results of ultra-micro-hardness tests are depicted in Fig. 8. Here, just three aging stages are shown since no results were available for the specimens aged with standardized artificial solar irradiation (sun). A maximum test force of $F_{\max }=98.07 \mathrm{mN}$ was chosen in order to evaluate an influence of thermal and light-induced aging on the micromechanical properties in the outer layers of the specimen. Figure $8 \mathrm{a}$ displays loaddisplacement curves. Qualitatively, the aged specimens exhibit lower values in indentation depths. Furthermore, differences in the slope of the loading and unloading phase of each curve can be observed, which indicate a change in the elastic-plastic deformation behavior of the aged Cottonid specimens. For the purpose of comparability of the characteristic values Martens hardness HM and indentation modulus $\mathrm{E}_{\mathrm{it}}$, Fig. $8 \mathrm{~b}$ shows the arithmetic mean and standard deviation of five measuring points for the initial condition, the thermal and the optical aged state. By comparison, the different aging stages show pronounced differences within the characteristic values. Compared to the initial condition, thermally aged specimens show a distinct increase of $\mathrm{HM}$ and $\mathrm{E}_{\mathrm{it}}$, which is also visible for the optically aged specimens, but less pronounced. So, as expected, thermal and light-induced aging seems to lead to an embrittlement of the outer, irradiated layers of the specimens, which can be verified by several other studies on polymeric materials, especially wood [41].

\section{Humidity-driven actuation}

Figure 9 shows the results of static actuation tests $\left(\mathrm{T}_{\mathrm{amb}}=23^{\circ} \mathrm{C}, \phi_{\mathrm{amb}}=95 \%\right.$ r.H., $\left.\mathrm{t}_{\mathrm{s}}=2.75 \mathrm{~h}\right)$ on the structurally optimized Cottonid variant M60Z50. True tangential strain $\varepsilon_{\text {Tan }}^{\prime}$, detected via DIC on the specimens' surfaces, is plotted over the swelling time $t_{s}$ and the influence of material thickness $t_{\text {mat }}$ as well as manufacturing direction on the humidity-driven swelling and shrinking behavior is characterized. Strains parallel to manufacturing direction $\left(0^{\circ} / \mathrm{X}\right)$ are indexed with $\mathrm{x}$, whereas strains perpendicular to manufacturing direction $\left(90^{\circ} / \mathrm{Y}\right)$ are indexed with $\mathrm{y}$.

In Fig. 9a, results are shown for M60Z50 specimens with $t_{\text {mat,thick }}=4.0 \mathrm{~mm}$ and $t_{\text {mat,thin }}=0.4 \mathrm{~mm}$. After a swelling time of $\mathrm{t}_{\mathrm{s}}=0.25 \mathrm{~h}, \boldsymbol{\varepsilon}_{\text {Tan,y,thin }}^{\prime}$ reaches its maximum with $\sim 2.5 \%$ compared to $\varepsilon_{\mathrm{T}, \mathrm{y} \text {, thick }}$ with $\sim 0.15 \%$. So, while the thin specimen shows a very adaptive behavior, the thick one is more or less dimensionally stable. At the end of the test at $\mathrm{t}_{\mathrm{s}}=2.75 \mathrm{~h} \varepsilon_{\text {Tan,y,thick }}^{\prime}$ increases up to $\sim 0.4 \%$ compared to the initial condition. With regard to the thin specimen with $\sim 2 \%$ at the end

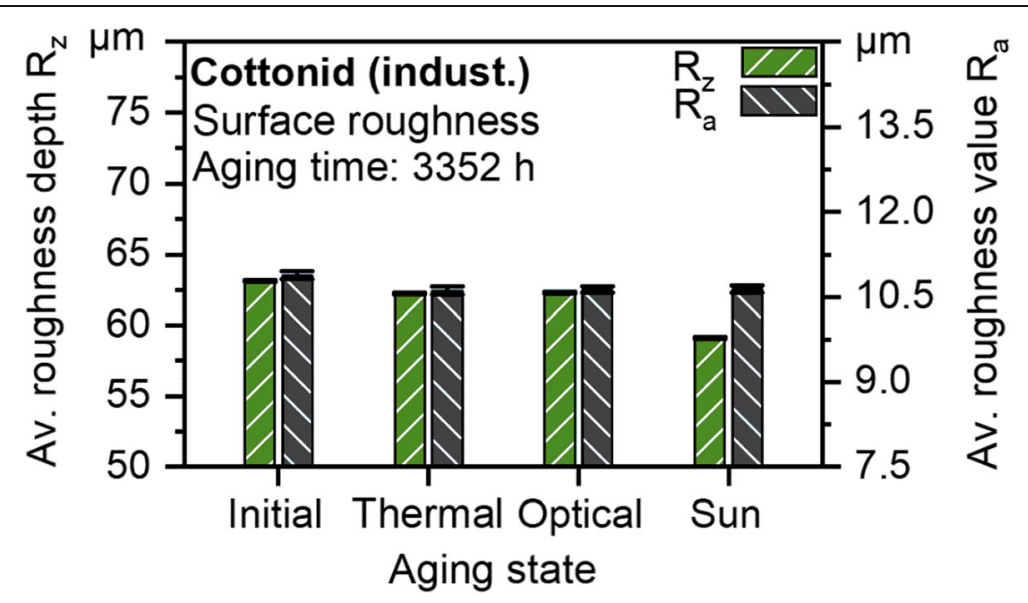

Fig. 7 Roughness measurements on surface of industrial Cottonid material (Ernst Krueger) in different aging stages 

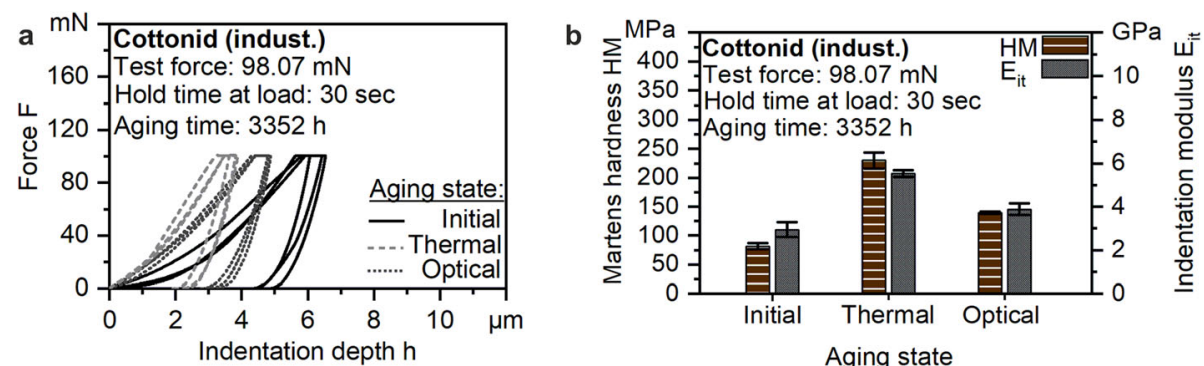

Fig. 8 Ultra-micro-hardness measurements on surface of industrial Cottonid material (Ernst Krueger) in different aging stages: a Force (F) indentation depth (h) curves, and $\mathbf{b}$ Obtained values for Martens hardness HM and indentation modulus $\mathrm{E}_{\mathrm{it}}$

of the test, this humidity-driven expansion is much lower. So it can be concluded, that humidity-driven actuation behavior of Cottonid is a function of the material thickness $t_{\text {mat }}$ and therefore by varying the amount of paper layers fed into the parchmentizing process either climate-adaptive elements for bioarchitectural issues or dimensionally stable components for conventional construction-related applications can be produced. A transitional material thickness $t_{\text {mat,trans }}$, where humiditydriven expansions of Cottonid are not justifiable anymore with regard to standards for conventional construction, will be defined in further investigations.

In Fig. 9b, showing results for the M60Z50 specimen with $\mathrm{t}_{\text {mat,thin }}=0.4 \mathrm{~mm}$, it becomes clear, that swelling due to water absorption is more pronounced perpendicular to manufacturing direction, since $\varepsilon_{\text {Tan,y,thin }}^{\prime}$ reaches a higher value of $\sim 2.5 \%$ compared to $\varepsilon_{\text {Tan, }, \text { thin }}^{\prime}=$ $1.5 \%$ after a swelling time of $t_{s}=0.25 \mathrm{~h}$. After reaching its maximum value, $\varepsilon^{\prime}$ Tan,y,thin decreases again and saturates after $\mathrm{t}_{\mathrm{s}}=0.75 \mathrm{~h}$ at $\sim 2 \%$. At $\mathrm{t}_{\mathrm{s}}=0.50 \mathrm{~h}, \varepsilon_{\text {Tan, } \mathrm{x} \text {,thin }}^{\prime}$ reaches its maximum, saturates at $\sim 2.25 \%$ and stays above $\varepsilon_{\text {Tan,y,thin }}^{\prime}$ until the end of the test. It can be concluded, that for short swelling times, the Y-orientation is favorable, while there seems to be no distinct difference in the materials' reaction when it comes to long-term humidity loading.

\section{Conclusions and outlook}

This study, focusing on the impact of solar radiation on chemical structure and micromechanical properties of the cellulose-based humidity-sensing material Cottonid, is an extract of a comprehensive experimental study on the influence of individual manufacturing parameters on the functional and mechanical properties of the biopolymeric material by means of instrumented actuation and fatigue assessments. It could be shown, that the impact of thermal loads in combination with solar radiation leads to chemical modifications of the cellulose on the surface of the aged Cottonid specimens. Infrared spectra revealed changes in adsorption at $2900 \mathrm{~cm}^{-1}$, i.e. the spectral region of $\mathrm{C}-\mathrm{H}$ stretching vibrations, and between 1800 and $1700 \mathrm{~cm}^{-1}$, i.e. the spectral region of $\mathrm{C}=\mathrm{O}$ stretching vibrations, and therefore indicate oxidative stress on the surface of the aged specimens $[4,17$, 18]. These findings are underlined with results of EPR spectroscopy, which indicate the presence of oxidationrelated radicals. The oxidative stress obviously provokes a decreased surface roughness leading to embrittlement, which could be verified by increased Martens hardness $\mathrm{HM}$ and indentation modulus $\mathrm{E}_{\mathrm{it}}$ assessed by ultra-microhardness tests. Therefore, a change in micromechanical surface properties of the aged Cottonid specimens due to chemical modifications induced by a combination of
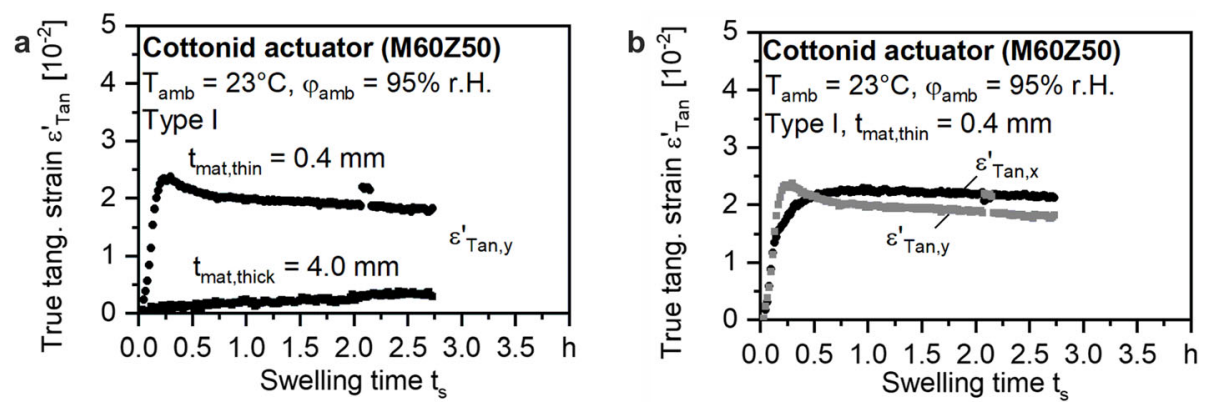

Fig. 9 Actuation tests on structurally optimized Cottonid variant M60Z50: a Influence of manufacturing direction, and $\mathbf{b}$ Influence of material thickness $t_{\text {mat }}$ 
thermal loads and solar irradiation could be observed [42-44]. Experiments with pure thermal loads induced comparable degradation effects to combined loads, whereas aging with a standardized artificial solar irradiation caused a more distinct material reaction compared to aging with short-wavelength blue light radiation [23]. These more or less material-specific reactions onto the induced loads could origin from the chemical modification of cellulose I in a not yet defined mix of cellulose I and II during the manufacturing process of Cottonid and have to be thoroughly investigated in further studies. Since for manufacturing of Cottonid the cellulose contained in the raw paper layers gets partly hydrolyzed by the help of a chemical catalyst, which was observed to be a stabilizing process in terms of light-induced radical reactions [17], these investigations will be of high interest to qualify Cottonid for outdoor applications. Further, since the presented results were obtained on industrial manufactured Cottonid material, which has a unique red color, it is essential to investigate and comparatively evaluate photodegradation mechanisms on colorless, i.e. white, Cottonid [17].

Actuation tests on the structurally optimized Cottonid variant M60Z50 revealed an influence of the material thickness $t_{\text {mat }}$ as well as of the predefined orientation of the cellulose micro fibrils. It can be stated, that Cottonid's actuation behavior is a function of its material thickness, i.e. a ten times thinner specimen achieves a ten times increased humidity-driven expansion. Furthermore, humidity-driven actuation is more pronounced perpendicular to micro fibril orientation, which is already described in various studies concerning cellulose-based materials $[2,26,45]$. These findings can be used for the development of climate-adaptive Cottonid elements capable of complex passive shape changes due to efficient and smart combination of microstructure and material thickness. Since Cottonid is manufactured by chemical modification of single paper layers, which are stacked to get thicker material, the adjustment and smart usage of these manufacturing parameters for tailor-made climate-adaptive element production can be easily implemented.

In summary, the conditions of the manufacturing process of Cottonid and its hygroscopic material behavior make the material ideal for the development of application-oriented adaptive elements capable of complex passive, humidity-driven shape changes with adjustable magnitude e.g. for construction-related applications. The aging experiments revealed an interaction of Cottonid with thermal and light-induced loads, which are expected in natural weathering conditions, i.e. environmental triggers, in this application field. The change in micromechanical properties and degradation processes, respectively, on the surface have to be considered for the prediction of the long-term behavior of climate-adaptive Cottonid elements.
Up to now the results show, that degradation takes place and that the modifications of the chemical structure also affect the micromechanical properties.

In further studies, it will be investigated how these mechanisms affect the macroscopic deformation behavior of Cottonid and its specific mechanical values, like Young's modulus and ultimate tensile strength, as well as the actuation behavior. For this, in a first step aging experiments will be conducted at different temperatures and relative humidity levels to assess the influence of weathering conditions on the degradation behavior. Furthermore, the customized specimen holder for actuation experiments can be equipped with LEDs, so that in the near future swelling and shrinking behavior can be characterized with superimposed thermal and light-induced loading.

\section{Acknowledgements}

The authors thank the Hahnmuehle FineArt GmbH (Dassel, Germany) and the Ernst Krueger GmbH \& Co. KG (Geldern, Germany) for providing raw material for Cottonid manufacturing and industrial reference material. The assistance during lab work of Mr. T. Graszynski is greatfully acknowledged.

\section{Authors' contributions}

R.S., M.L. and M.H. performed experiments, prepared figures and wrote the manuscript. F.W., C.Z. and J.M. supervised the project. The author(s) read and approved the final manuscript.

\section{Funding}

The authors thank the German Research Foundation (Deutsche Forschungsgemeinschaft, DFG) for funding the research project

"Biomechanical qualification of the structure-optimized functional material Cottonid as an adaptive element" (WA 1672/23-1, ZO 113/22-1). Open Access funding enabled and organized by Projekt DEAL.

\section{Availability of data and materials}

The datasets used and/or analyzed during the current study are available from the corresponding author on reasonable request.

\section{Declarations}

Competing interests

The authors declare that they have no competing interests.

\section{Author details}

'Department of Materials Test Engineering (WPT), TU Dortmund University, Baroper Str. 303, D-44227 Dortmund, Germany. ${ }^{2}$ Biogenic Polymers, TUM Campus Straubing for Biotechnology and Sustainability, Schulgasse 16 D-94315 Straubing, Germany. ${ }^{3}$ Photonics and Material Science, Hamm-Lippstadt University of Applied Science, Marker Allee 76-78, D-59063 Hamm, Germany.

Received: 9 October 2020 Accepted: 11 March 2021

Published online: 06 April 2021

\footnotetext{
References

1. M. Wei, Y. Gao, X. Li, M.J. Serpe, Stimuli-responsive polymers and their applications. Polym. Chem. 8(1), S127-S143 (2017)

2. M. Rueggeberg, I. Burgert, Bio-inspired wooden actuators for large scale applications. PLoS One 10(3), e0120718 (2015). https://doi.org/10.1371/ journal.pone. 0120718

3. S. Poppinga, C. Zollfrank, O. Prucker, J. Ruehe, A. Menges, T. Cheng, T. Speck, Toward a new generation of smart biomimetic actuators for architecture. Adv. Mater. 30(19), e1703653 (2018). https://doi.org/10.1 002/adma.201703653

4. T. Taylor. U.S. patent 114,880, 16 March 1871
} 
5. T. Toratti, S. Svensson, Mechani-sorptive experiments perpendicular to grain under tensile and compressive loads. Wood Sci. Technol. 34, 317-326 (2000)

6. I. Burgert, T. Keplinger, E. Cabane, V. Merk, R. Rueggeberg, in Secondary xylem biology: origin, functions, and applications. Biomaterial wood: woodbased and bioinspired materials (2016), pp. 259-281. https://doi.org/10.101 6/B978-0-12-802185-9.00013-9

7. L. Guiducci, J.C. Weaver, Y.J.M. Bréchet, P. Fratzl, J.W.C. Dunlop, The geometric design and fabrication of actuating cellular structures. Adv. Mater. Interfaces 2(11), 1500011 (2015). https://doi.org/10.1002/admi.201500011

8. Q. Zhu, Y. Jin, W. Wang, G. Sun, D. Wang, Bioinspired smart moisture actuators based on nanoscale cellulose materials and porous, hydrophilic EVOH nanofibrous membranes. ACS Appl. Mater. Interfaces 11(1), 14401448 (2019). https://doi.org/10.1021/acsami.8b17538

9. M. Dai, O.T. Picot, J.M.N. Verjans, L.T. de Haan, A.P.H.J. Schenning, T. Peijs, C. W.M. Bastiaansen, Humidity-responsive bilayer actuators based on a liquidcrystalline polymer network. ACS Appl. Mater. Interfaces 5(11), 4945-4950 (2013). https://doi.org/10.1021/am400681z

10. W. Hilber, Stimulus-active polymer actuators for next-generation microfluidic devices. Appl. Phys. A Mater. Sci. Process. 122(751), 1-40 (2016). https://doi. org/10.1007/s00339-016-0258-6

11. P. Groenquist, F.K. Wittel, M. Rueggeberg, Modeling and design of thin bending wooden bilayers. PLoS One 13(10), e0205607 (2018). https://doi. org/10.1371/journal.pone.0205607

12. C. Vailati, E. Bachtiar, P. Hass, I. Burgert, M. Rueggeberg, An autonomous shading system based on coupled wood bilayer elements. Energy Build. 158, 1013-1022 (2018). https://doi.org/10.101 6/j.enbuild.2017.10.042

13. A. Patera, D. Derome, M. Griffa, J. Carmeliet, Hysteresis in swelling and in sorption of wood tissue. J. Struct. Biol. 182(3), 226-234 (2013). https://doi. org/10.1016/j.jsb.2013.03.003

14. H. Fan, G. Li, F. Yang, L. Yang, S. Zhang, Photodegradation of cellulose under UV light catalysed by TiO2. J. Chem. Technol. Biotechnol. 86(8), 11071112 (2011). https://doi.org/10.1002/jctb.2632

15. E. Yousif, R. Haddad, Photodegradation and photostabilization of polymers, especially polystyrene: review. SpringerPlus 2(398), 1-32 (2013). https://doi. org/10.1186/2193-1801-2-398

16. S. Al-Malaika, Reactive modifiers for polymers - An A-Z reference (Springer, Netherlands, 1997)

17. T.N. Kleinert, Damage in cellulosic textiles caused by aging and light (in German). Lenz. Rep. 25, 33-40 (1968)

18. M. Yatagai, S.H. Zeronian, Effect of ultraviolet light and heat on the properties of cotton cellulose. Cellulose 1, 205-214 (1994)

19. D. N-S Hon, Photooxidative degradation of cellulose: reactions of the cellulosic free radicals with oxygen. J. Polym. Sci.: Polym. Chem. Ed. 17, 441454 (1979)

20. C. Lin, T. Zeng, Q. Whang, I. Huang, Y. Ni, F. Huang, X. Ma, S. Cao, Effects of the conditions of the TEMPO/NaBR/NAClO system on the carboxyl groups, degree of polymerization, and yield of the oxidized cellulose. BioResources 13(3), 5965-5975 (2018)

21. D. N-S Hon, S.-T. Chang, Surface degradation of wood by ultraviolet light. J. Polym. Sci.: Polym. Chem. Ed. 22, 2227-2241 (1984)

22. S.Y. Oh, D.I. Yoo, Y. Shin, G. Seo, FTIR analysis of cellulose treated with sodium hydroxide and carbon dioxide. Carbohydr. Res. 340(3), 417-428 (2005). https://doi.org/10.1016/j.carres.2004.11.027

23. F. Schneider, K. Moebius, Analysis of electron resonance spectra of organic radicals (in German). J. Nat. Res. 18b, 1111-1119 (1963)

24. G. Geuskens, in Degradation of polymers, ed. by C. H. Bamford, C. F. H. Tipper. (Elsevier Scientific Pub. Co, 1975), pp. 420-424

25. J. Baltscheit, N. Schmidt, F. Schroeder, J. Meyer, Investigations on the aging behavior of transparent bioplastics for optical applications. InfoMat 2(2), 424-433 (2020). https://doi.org/10.1002/inf2.12065

26. M. Hemmerich, R. Scholz, S. Saha, F. Walther, J. Meyer, Polylactid - a suitable bio-based plastic for optical applications? - Test setup for accelerated optical and thermal aging. Special issue Chrom. Food Forum (03), 43-45 (2019)

27. M. Hemmerich, J. Meyer, F. Walther, Evaluation on the renewable bioplastic polyactid for optical elements in lighting systems (in German). Progression in materials testing for research and practice (in German). ed. by J-B Langer, M Waechter. Conference materials testing, online-event, December 2020. (Stahleisen, Duesseldorf, 2020)
28. Y. Hishikawa, E. Togawa, T. Kondo, Characterization of individual hydrogen bonds in crystalline regenerated cellulose using resolved polarized FTIR spectra. ACS Omega 2(4), 1469-1476 (2017). https://doi.org/10.1021/a csomega.6b00364

29. K. Esch, X-ray diffraction on paper and vulcanized fiber (in German). Doctoral thesis, TU Dortmund University (2018). Dortmund. Online available: https://katalog.ub.tu-dortmund.de/id/ir01388a:ubd.lobid:HT019692146. doi: https://doi.org/10.17877/DE290R-18877

30. R.-M. Mittendorf, Development of a guideline for technical design of screw connections in vulcanized fiber (in German). Doctoral thesis, TU Dortmund University (2016). Dortmund. Online available: https://katalog.ub.tudortmund.de/id/ir01388a:ubd.lobid:HT018929719. doi: https://doi.org/10.1 7877/DE290R-16913

31. A.D. French, Idealized powder diffraction patterns for cellulose polymorphs. Cellulose 21(2), 885-896 (2014). https://doi.org/10.1007/s1 0570-013-0030-4

32. M. Schestakow, I. Karadagli, L. Ratke, Cellulose aerogels prepared from an aqueous zinc chloride salt hydrate melt. Carbohydr. Polym. 137, 642-649 (2016). https://doi.org/10.1016/j.carbpol.2015.10.097

33. R. Scholz, R.-M. Mittendorf, J.K. Engels, A. Hartmaier, B. Kuenne, F. Walther, Direction-dependent mechanical characterization of cellulose-based composite vulcanized fiber. Mater. Test. 58(10), 813-817 (2016). https://doi. org/10.3139/120.110929

34. R. Scholz, M. Langhansl, C. Zollfrank, F. Walther, Cottonid - an efficient functional material for humidity-driven actuators (in German). Smart Structures and Systems (in German), ed. by T Melz, M Wiedemann. 4SMARTSSymposiums, Darmstadt, May 2019 (Shaker, Herzogenrath, 2019), p. 63-75

35. R. Scholz, M. Langhansl, C. Zollfrank, F. Walther, Experimental study on the actuation and fatigue behavior of the biopolymeric material Cottonid. Mater. Tod.: Proc. 7, 476-483 (2019). https://doi.org/10.1016/j.matpr.201 8.11 .112

36. R. Scholz, M. Langhansl, C. Zollfrank, F. Walther, Humidity-sensing material Cottonid - microstructural tuning for improved actuation and fatigue performance. Front. Mater. 7, 1-10 (2020). https://doi.org/10.3389/fmats.202 0.00156

37. R. Scholz, A. Delp, F. Walther, In situ characterization of damage development in Cottonid due to quasi-static tensile loading. Materials 13(9), 1-12 (2020). https://doi.org/10.3390/ma13092180

38. V. Hospodarova, E. Singovszka, N. Stevulova, Characterization of cellulosic fibers by FTIR spectroscopy for their further implementation to building materials. Am. J. Anal. Chem. 09(06), 303-310 (2018). https://doi.org/10.423 6/ajac.2018.96023

39. M. Poletto, H.L. Ornaghi, A.J. Zattera, Native cellulose: structure, characterization and thermal properties. Materials 7(9), 6105-6119 (2014). https://doi.org/10.3390/ma7096105

40. M. Hauptmann, U. Mueller, M. Obersriebnig, W. Gindl-Altmutter, A. Beck, C. Hansmann, The optical appearance of wood related to nanoscale surfce roughness. Wood look \& roughness. BioResources 8(3), 4038 4045 (2013)

41. L. Gurau, H. Mansfield-Williams, M. Irle, Filtering the roughness of a sanded wood surface. Int. Wood Prod. J. 64(5), 363-371 (2006). https://doi.org/10.1 007/s00107-005-0089-1

42. A.O. Rapp, C. Brischke, C.R. Welzbacher, Interrelationship between the severity of heat treatments and sieve fractions after impact ball milling: a mechanical test for quality control of thermally modified wood. Wood Res. 60(1), 64-70 (2006). https://doi.org/10.1515/HF.2006.012

43. A. Flores, N.D. Jordan, F.J. Baltà-Calleja, D.C. Bassett, R.H. Olley, N.G. Smith, Mechanical changes linked to embrittlement at the wear surface of polyethylene implants in hip joints. Polymer 41(21), 7635-7639 (2000). https://doi.org/10.1016/S0032-3861(00)00132-4

44. M.P. Arrieta, J. López, Mechanical characterization of microlaminar structures extracted from cellulosic materials using nanoindentation technique. Cellul. Chem. Technol. 47(5-6), 345-351 (2013)

45. M. Frey, D. Widner, J.S. Segmehl, K. Casdorff, T. Keplinger, I. Burgert, Delignified and densified cellulose bulk materials with excellent tensile properties for sustainable engineering. ACS Appl. Mater. Interfaces 10(5), 5030-5037 (2018). https://doi.org/10.1021/acsami.7b18646

\section{Publisher's Note}

Springer Nature remains neutral with regard to jurisdictional claims in published maps and institutional affiliations. 